\title{
Improvement of a rivet geometry for the self-piercing riveting of high-strength steel and multi-material joints
}

\author{
Benedikt Uhe $^{1} \cdot$ Clara-Maria Kuball $^{2} \cdot$ Marion Merklein $^{2} \cdot$ Gerson Meschut $^{1}$
}

Received: 26 November 2019 / Accepted: 24 July 2020 / Published online: 2 August 2020

(c) The Author(s) 2020

\begin{abstract}
As a result of lightweight design, increased use is being made of high-strength steel and aluminium in car bodies. Selfpiercing riveting is an established technique for joining these materials. The dissimilar properties of the two materials have led to a number of different rivet geometries in the past. Each rivet geometry fulfils the requirements of the materials within a limited range. In the present investigation, an improved rivet geometry is developed, which permits the reliable joining of two material combinations that could only be joined by two different rivet geometries up until now. Material combination 1 consists of high-strength steel on both sides, while material combination 2 comprises aluminium on the punch side and high-strength steel on the die side. The material flow and the stress and strain conditions prevailing during the joining process are analysed by means of numerical simulation. The rivet geometry is then improved step-by-step on the basis of this analysis. Finally, the improved rivet geometry is manufactured and the findings of the investigation are verified in experimental joining tests.
\end{abstract}

Keywords Self-piercing riveting $\cdot$ Joining technology $\cdot$ Rivet geometry $\cdot$ Multi-material design $\cdot$ High-strength steel · Aluminium

\section{Introduction}

The lightweight design of car bodies is leading to the increased use of high-strength steel and aluminium [1]. Self-piercing riveting (SPR) is a common mechanical joining technique used to join these materials in series production [2]. In particular, the combination of SPR and adhesive bonding turns out to be beneficial [3]. A typical application example for the use of SPR is described in [4]. The four stages of the SPR process are demonstrated in Fig. 1.

Two or more sheets are clamped between a blank holder and a die. A punch presses a semi-tubular rivet into the sheets. The rivet pierces the sheet on the punch side and then, as the rivet flares, an interlock is created [5]. The central components of SPR are the rivet and the die. The die is

Benedikt Uhe

benedikt.uhe@1wf.upb.de

1 Laboratory for Material and Joining Technology (LWF), Paderborn University, 33098 Paderborn, Germany

2 Institute of Manufacturing Technology (LFT), Friedrich-A lexander-Universität Erlangen-Nürnberg, 91058 Erlangen, Germany characterised by its diameter, its depth and any shape elements like mandrels, while the rivet is characterised by its geometry, the material used, the condition of the material and the coating. The characteristic geometry parameters as per [6] are shown in Fig. 2. The rivet and die are selected individually for each material combination as a function of the strength, ductility and thickness of the sheets to be joined [7]. Aluminium and high-strength steel have dissimilar requirements in this respect. The present investigation focuses on two different material combinations. Material combination 1 ( $\mathrm{MC} \mathrm{1)} \mathrm{consists} \mathrm{of} \mathrm{high-strength} \mathrm{steel}$ HCT780X on both sides. Material combination 2 (MC 2) has aluminium EN AW-5083 on the punch side and steel HCT780X on the die side. All the sheets have a thickness of $1.5 \mathrm{~mm}$. As determined in experimental tests, the yield strength of the steel HCT780X is $565 \mathrm{MPa}$ and the tensile strength $861 \mathrm{MPa}$ at an elongation of $12.4 \%$. The yield strength of the aluminium EN AW-5083 is $157 \mathrm{MPa}$ and the tensile strength $292 \mathrm{MPa}$ at an elongation of $18 \%$.

Steel is normally located on the punch side on account of its high strength and low ductility. In this case, the sheet on the punch side is pierced with a low level of deformation. This results in a slug, which remains under the rivet 
Fig. 1 SPR process stages

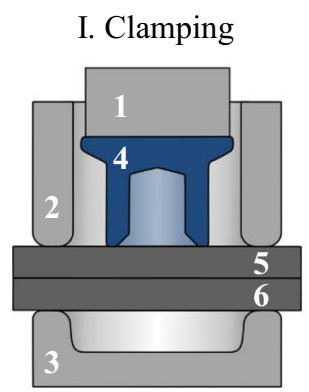

II. Piercing

III. Flaring

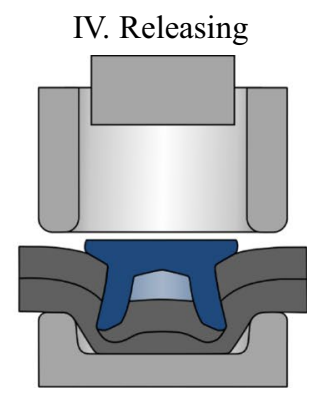

1: Punch 2: Blank holder 3: Die 4: Rivet 5: Punch-sided sheet

6: Die-sided sheet

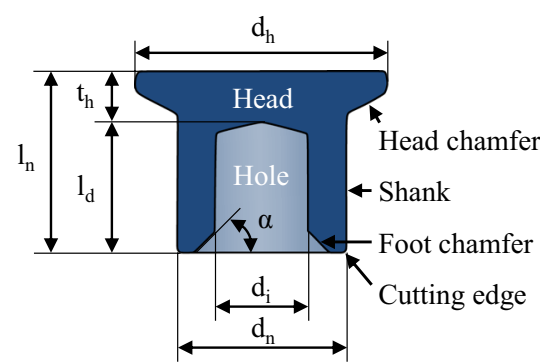

$\mathrm{d}_{\mathrm{h}}:$ Head diameter

$\mathrm{d}_{\mathrm{i}}$ : Inner diameter

$\mathrm{d}_{\mathrm{n}}$ : Nominal diameter

$1_{\mathrm{d}}$ : Hole depth

$1_{\mathrm{n}}$ : Nominal length

$\mathrm{t}_{\mathrm{h}}$ : Head thickness

$\alpha$ : Foot angle

Fig. 2 Characteristic geometry parameters in the cross-section of a severed rivet

and supports rivet flaring. A flat die is suitable in this case. The rivet shank must have sufficient stiffness to withstand the load during the piercing operation, otherwise the rivet can crack and be bent or compressed [8]. If there is highstrength steel on the die side, the low ductility poses problems, since this impairs the flaring of the rivet and cracks can occur in the sheet on the die side [9]. Aluminium is normally located on the die side on account of its high ductility. When aluminium is positioned on the punch side, the material is pushed into the hole in the rivet, which thus needs to have a sufficiently large volume. A sharper rivet foot supports the piercing of the aluminium and leads to a larger interlock [10]. To join aluminium on the punch side with highstrength steel on the die side, it is necessary to use a die with a mandrel [11].

The differences in the material properties have prompted the development of several different rivet geometries in the past. Each rivet geometry fulfils the requirements of the materials within a limited range. The sampling conducted in the context of the present investigation, however, shows that there is currently no series rivet that can meets the requirement for joining the two material combinations under consideration with just a single rivet geometry. The aim of the present investigation is thus to develop an improved rivet geometry that will permit both material combinations to be reliably joined. This rivet geometry must be guaranteed to achieve the required values for the characteristic joint parameters, as shown in Fig. 3, and also ensure freedom

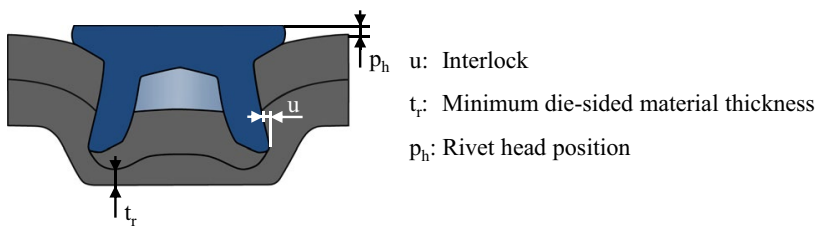

Fig. 3 Characteristic joint parameters in the cross-section of a severed joint

Table 1 Rivets and dies selected, based on the sampling

\begin{tabular}{lllll}
\hline MC & Rivet & \multicolumn{3}{c}{ Die } \\
\hline 1 & Geometry & P 5.2 $\times 5.5 \mathrm{SK}$ & Shape & Flat \\
& Material & Steel $38 \mathrm{~B} 2$ & Diameter & $8.4 \mathrm{~mm}$ \\
& Hardness level & $480 \pm 30 \mathrm{HV} 10$ & Depth & $2.0 \mathrm{~mm}$ \\
& Coating & Almac $^{\circledR}$ & & \\
2 & Geometry & HD2 5.3 $\times 4.5 \mathrm{SK}$ & Shape & Mandrel \\
& Material & Steel 38B2 & Diameter & $8.5 \mathrm{~mm}$ \\
& Hardness level & $480 \pm 30 \mathrm{HV} 10$ & Depth & $2.0 \mathrm{~mm}$ \\
& Coating & Almac $^{\circledR}$ & & \\
\hline
\end{tabular}

from cracks in the joint. Bending and compression of the rivet must be avoided and it must be possible for the rivet geometry to be manufactured by cold forming and fed to the riveting system using standard equipment.

\section{Sampling of the material combinations and modelling of the joining process}

Experimental sampling is performed in order to select suitable series rivets and dies for SPR of the two material combinations. As riveting system, a tongs of type $\mathrm{TOX}^{\circledR} \mathrm{TE}-\mathrm{X}$ 80.250 .351 , which can be mounted on industrial robots, is used for this purpose. This tongs consists of a C-bow, an electromechanical drive and the joining tools. These tools are designed as shown in Fig. 1. The joining velocity is $80 \mathrm{~mm} / \mathrm{s}$. The selected rivets and dies are listed in Table 1 . The solid P-rivet is suitable for material combination 1. 
Nevertheless, cracks occasionally occur at the transition from the rivet shank to the rivet head. Slight compression of the rivet can be observed. The sampling also shows, however, that the P-rivet is too massive for material combination 2 and causes the steel sheet on the die side to fracture. The other way round, the HD2-rivet is not stiff enough to pierce the steel sheet in material combination 1 . The rivet is simply compressed.

After the experimental sampling, the joining process is analysed by means of numerical simulation. As in previous investigations into SPR [12], a 2D axisymmetric model is generated (see Fig. 4). The software Simufact.forming 16 is used for this purpose. The tools are modelled as rigid bodies. The blank holder is coupled to the punch by a spring. Elastic-plastic material behaviour is defined for the rivet and the sheet. The flow curves of the rivet material and the sheet materials are based on experimental tests and approximated with the approach of Hockett-Sherby [13]. A mesh of quad elements with local refinement is used for the rivet and the sheets. The element size is $25 \mu \mathrm{m}$ in the

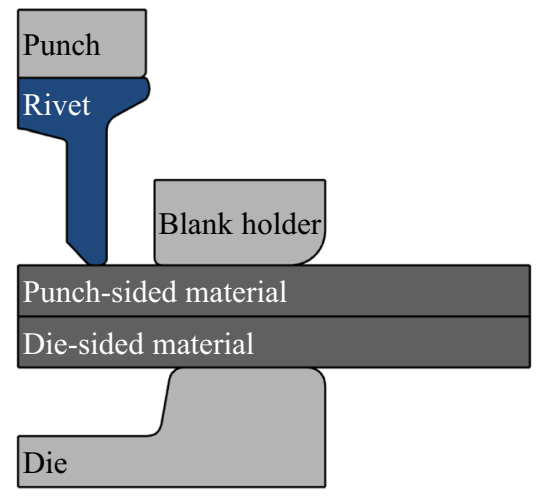

areas with the highest level of refinement. Remeshing of distorted finite elements is also employed. A damage criterion based on Cockroft-Latham is applied for the piercing of the punch-sided steel sheet of material combination 1 [14].

The separation of the punch-sided aluminium sheet in material combination 2 is modelled by a geometric criterion, while the friction is modelled by a combined friction law. The parameters for material separation and also the friction parameters are determined inversely by means of experimental data. In order to validate the numerical model, it is necessary to compare the results of the experiments and the simulations [15]. A comparison of the experiments and simulations for the cross-sections and force-stroke curves is shown in Fig. 5. For this, the stiffness influence of the $\mathrm{C}$-bow has been removed from the experimental force-stroke curves.

A comparison of the characteristic joint parameters from experiments and simulations is shown in Fig. 6. Also shown are the required values for the characteristic joint parameters in the present investigation. These values are based on standard specifications for industrial applications. The values for the interlock and the head position determined in the simulation come within the scatter range of the experiments. Only the minimum die-sided material thickness is undervalued by up to $10 \%$ in the simulation. The characteristic joint parameters that result when using the improved rivet developed within the present investigation are included for purposes of comparison.

Fig. 4 Numerical model

Fig. 5 Comparison of experiments and simulations for the sampled joints

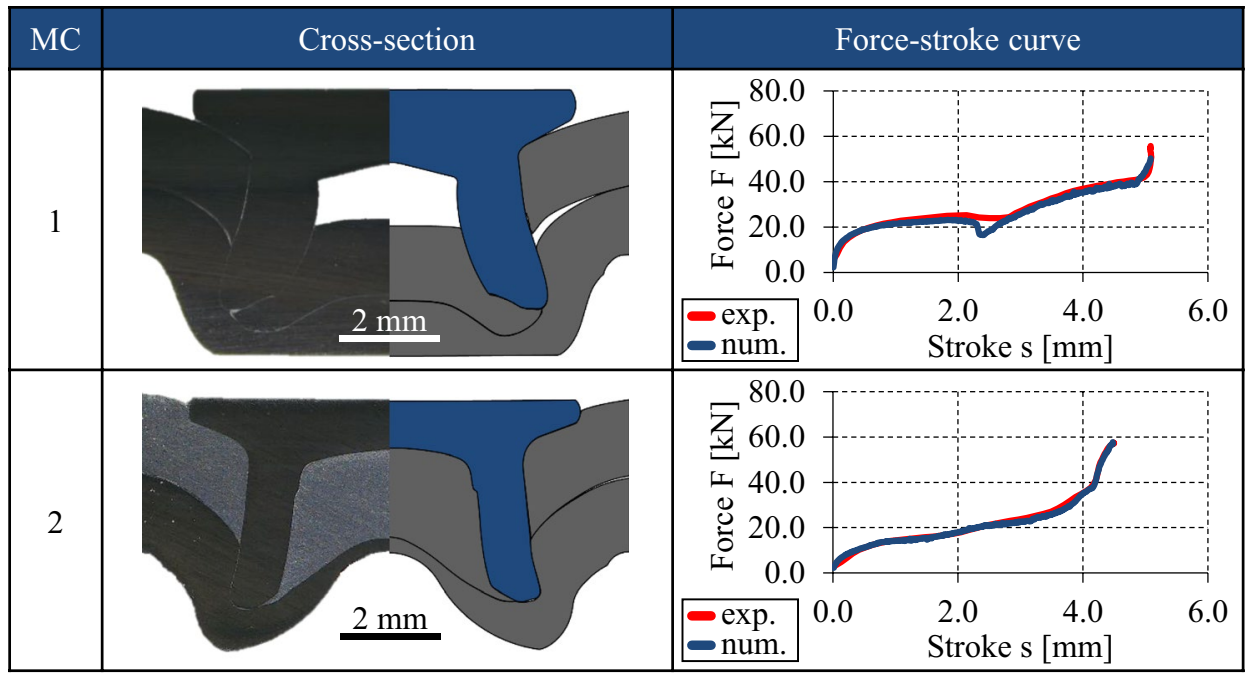


Fig. 6 Measured and simulated characteristic joint parameters
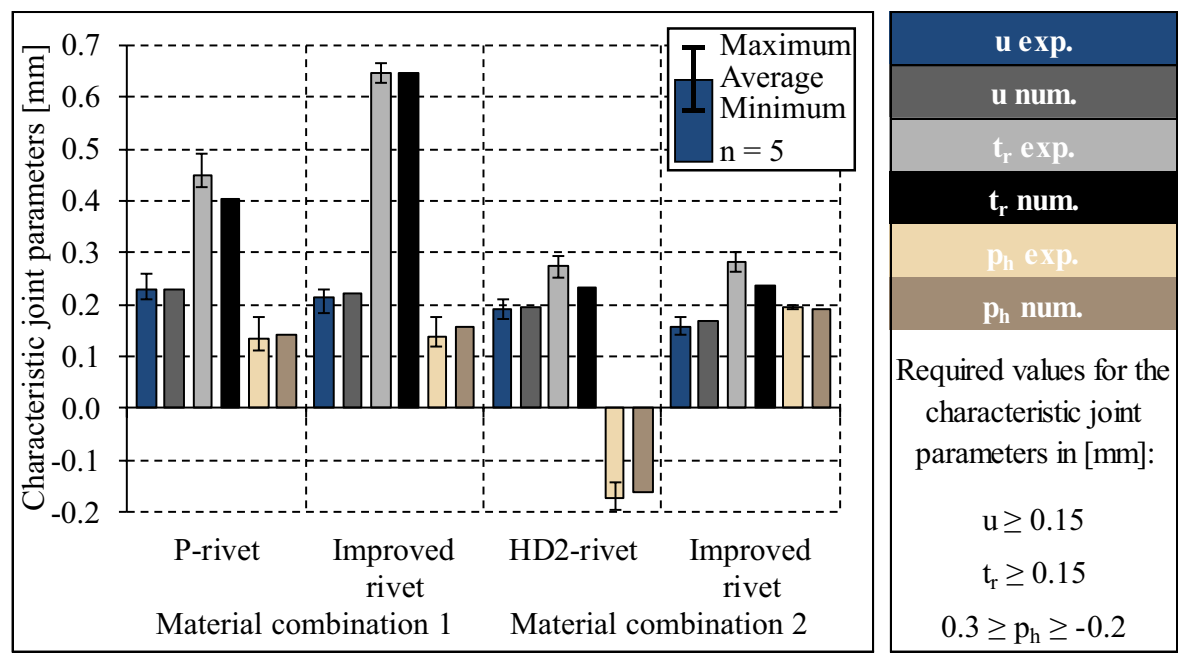

\section{Analysis of the process and improvement of the rivet geometry}

An improved rivet geometry is developed within the present investigation on the basis of the geometries of the P-rivet and the HD2-rivet. Since it has to be possible for the improved rivet to be fed to the riveting system using standard equipment, the head diameter is kept at $7.75 \mathrm{~mm}$, which is also the head diameter of the series rivets. The length of the improved rivet is set to $5.0 \mathrm{~mm}$, which is a common rivet length and just between the lengths of the P-rivet and the HD2-rivet. A rivet length of $5.5 \mathrm{~mm}$ would cause a fracture in the sheet on the die side in material combination 2. Using a rivet with a length of $4.5 \mathrm{~mm}$, the required value for the interlock as specified in Fig. 6 cannot be attained in material combination 1 , even for a die with a lower depth. In [16], the joining range of one rivet geometry was extended through the development of an optimised die shape and, in [17], a new die concept was developed to achieve better joining results. However, an analysis of the material flow shows that the dies used for the sampling are already the best choice, given the requirements of the materials in the present investigation. The development thus focuses solely on the rivet geometry. In the cross-section of the joints with material combination 1 , cracks are observed in the cross-section at the transition from the shank to the head of the P-rivet. It is essential to avoid cracks in the rivet for reliable joining. To find the reason for the cracks, the stress and strain conditions in the series rivets during and after the joining process are analysed by means of numerical simulation. Figure 7 shows the simulated stress and strain conditions in the rivets after release of the tools. The highest maximum principal stress of $\sigma_{1}=2223 \mathrm{MPa}$ occurs in the P-rivet at the transition from the shank to the head during the return stroke of the punch. After the release of the tools, the highest maximum principal stress in the P-rivet is $\sigma_{1}=2136 \mathrm{MPa}$. The highest

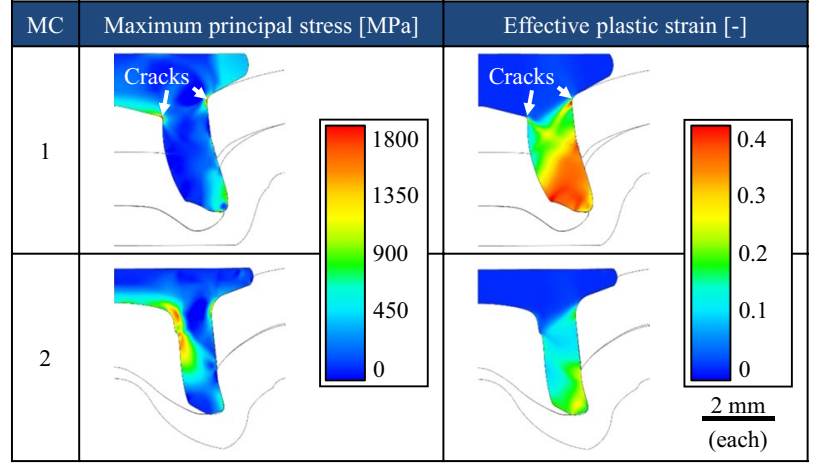

Fig. 7 Simulated stress and strain conditions in the series rivets after release of the tools

plastic strain under the rivet head is $\varphi=0.47$. The cracks in the experimental tests are located in the region of the stress and strain peaks. [18] also observed cracks after the release of the tools and investigated the stress increase during the return stroke of the punch and the residual stress in the rivet. In [19], the residual stress in the rivet is investigated under several different joining conditions. For a material combination with steel on the punch side, the residual stress is higher than for a material combination with aluminium on the punch side. When the joining process for the combinations being studied in the present investigation is simulated, the same results are found.

The stress and strain conditions in the HD2-rivet are less critical than those in the P-rivet. Only around the notch on the inner rivet shank does the highest maximum principal stress increase to $\sigma_{1}=1967 \mathrm{MPa}$ during the return stroke of the punch. The highest plastic strain under the rivet head is $\varphi=0.19$. At the transition from the rivet shank to the rivet head, the stress is even lower. One reason for this is the lower spring back of the aluminium compared to the steel. 
The spring back of the sheet on the punch side is responsible for the increase in stress during the return stroke of the tools and for the residual stress. A second reason is the rounded transition from the rivet shank to the rivet head. In order to prevent cracks in the rivet, the stress and strain peaks must be reduced by improving the rivet geometry. For this reason, the improved rivet geometry is designed to be stress-optimised. Notches and rough transitions are avoided. Another way to reduce the stress and strain peaks under the rivet head is by bevelling the outer rivet shank. The bevelling of the rivet shank means that the sheet on the punch side is not only clamped by the rivet head but also by the rivet shank, thus reducing the influence of the spring back. Another positive effect is achieved by reinforcing the rivet shank. This prevents the rivet from bending and compression. Bevelling the rivet shank, however, makes the flaring of the rivet more difficult. A bevel with an angle of $2^{\circ}$ for a nominal diameter of $5.3 \mathrm{~mm}$ is determined to be the best value. With a smaller angle, the stress and strain peaks cannot be sufficiently reduced and, with a larger angle, the values achieved for the interlock are too low. The underhead angle of the P-rivet allows gap-free contact between the rivet head and the punch-sided sheet. The head geometry of the P-rivet is thus retained. With the nominal diameter of $5.3 \mathrm{~mm}$ and the reinforcement of the rivet through bevelling, the inner diameter can be extended by comparison to the P-rivet. A minimum inner diameter of $3.2 \mathrm{~mm}$ is necessary to avoid bending and compression of the rivet in material combination 1 . Nevertheless, the inner diameter is still lower than the inner diameter of the HD2-rivet, which means that the shank is stiffer and the flaring of the rivet during the joining of material combination 2 is more difficult. Hence, the rivet foot is adjusted. A sharper rivet foot supports the flaring of the rivet. However, due to the piercing process in material combination 1 , the width of the rivet end face is retained from the P-rivet so as to have a sufficient crosssectional area of the shank. Increasing the foot angle from $45^{\circ}$ to $60^{\circ}$ leads to a sufficient interlock and supports the piercing of the aluminium in material combination 2 . In material combination 2 , the aluminium on the punch side is pushed into the hole of the rivet. An adequate hole volume thus is necessary. The hole volume of the P-rivet is too small to accommodate all the aluminium. This causes the material on the die side to fracture. Because of that, the hole depth of the improved rivet is extended to $4.4 \mathrm{~mm}$. With this value, the punch-sided aluminium fills the hole volume without any internal pressure, ensuring that the rivet and the material on the die side are not negatively influenced. For joining material combination 1, the influence of the hole depth is not as relevant as for joining material combination 2 , because the slug remains under the rivet and solely a small part of the material is pushed into the hole. Only the geometry of the shank and the foot are of importance for the deformation of

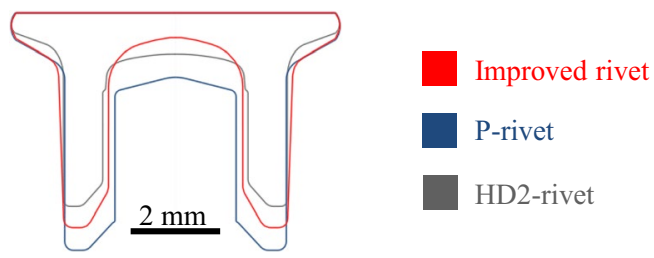

Fig. 8 Comparison of the improved rivet geometry with the P-rivet and the HD2-rivet

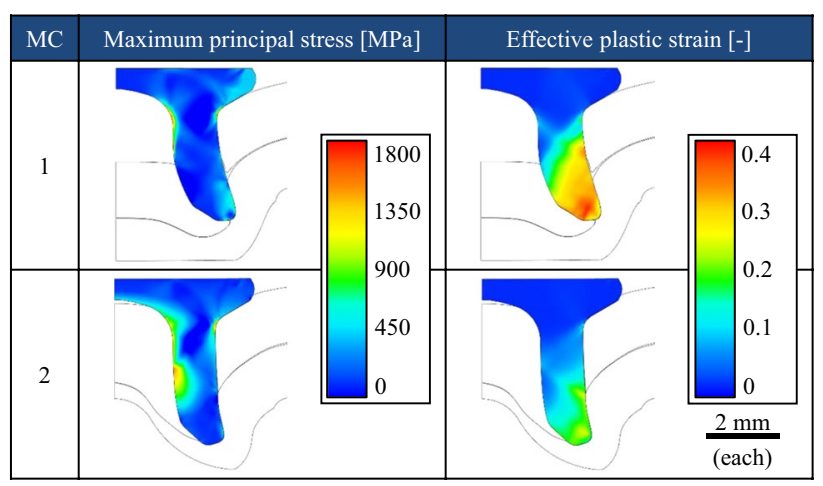

Fig. 9 Simulated stress and strain conditions in the improved rivet after release of the tools

the rivet. The improved rivet geometry is compared with the P-rivet geometry and the HD2-rivet geometry in Fig. 8.

The joining result and the stress and strain conditions in the improved rivet after release of the tools are shown in Fig. 9. When joining material combination 1, the highest maximum principal stress occurs during the return stroke of the punch in the region of the inner shank and is $\sigma_{1}=1830 \mathrm{MPa}$. The highest plastic strain under the rivet head is $\varphi=0.23$.

No stress or strain peaks occur. The highest maximum principal stress when joining material combination 2 is $\sigma_{1}=1813 \mathrm{MPa}$ and also occurs in the region of the inner shank. The highest plastic strain under the rivet head is $\varphi=0.14$.

\section{Experimental verification of the simulation results}

To validate the results of the simulation in experimental tests, rivets made of steel 38B2 are manufactured by turning. These rivets are quenched and tempered to a hardness level of $480 \pm 30 \mathrm{HV} 10$ and coated with Almac ${ }^{\circledR}$. With the exception of their geometry, the rivets thus have similar properties to the series rivets. Experimental joining tests using the same riveting system and the same joining velocity as for the sampling are carried out. A comparison of 
Fig. 10 Comparison of simulations and experiments for the improved rivet geometry

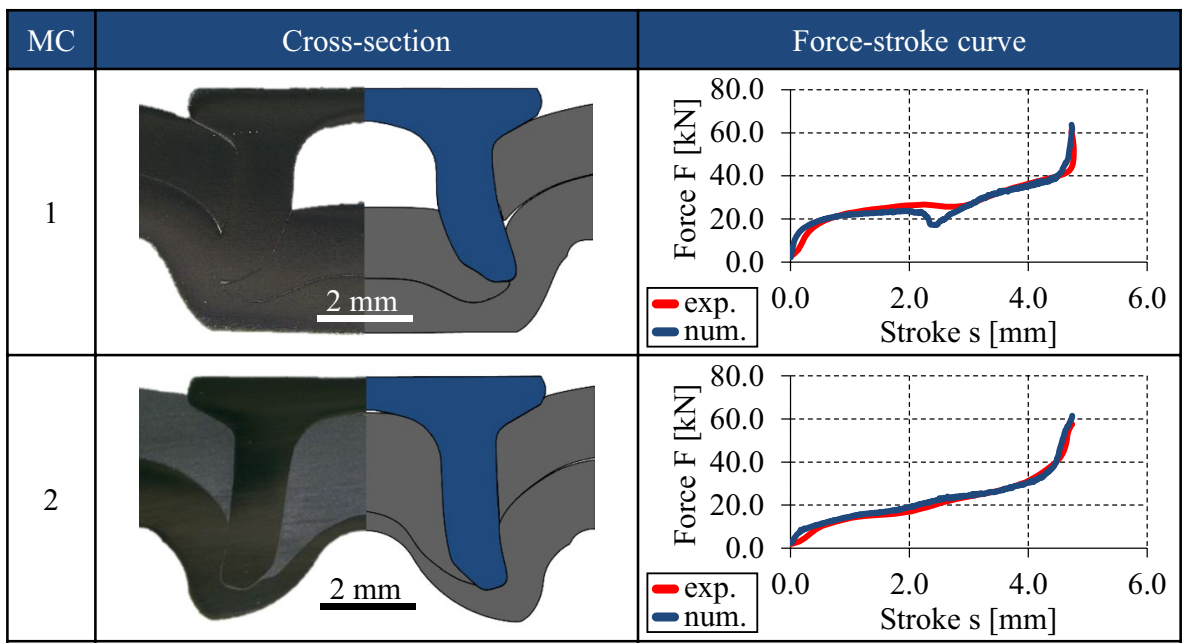

the experiments and simulations for the cross-sections and force-stroke curves is shown in Fig. 10. The measured values of the characteristic joint parameters are listed in Table 1. Step-by-step grinding shows that the experimental specimens are free of cracks. On the basis of the experimental results, it can be stated that the rivet geometry developed fulfils all the requirements and permits the reliable joining of both material combinations.

\section{Summary and outlook}

Up until now, two different rivet geometries have been necessary for SPR joining of the two material combinations used in the present investigation. This is demonstrated by experimental sampling employing series rivets. The present results summarise the development of an improved rivet geometry which permits both the material combinations under consideration to be reliably joined with just a single rivet geometry. The simulation-supported development of the improved rivet geometry is based on a knowledge of the materials' requirements and an analysis of the material flow of the sheets, the deformation of the rivet and the stress and strain conditions prevailing in the rivets. The development focuses on fulfilling the specified characteristic joint parameters and also on reducing the stress and strain peaks that occur in the rivet so as to prevent cracks as well as any bending and compression of the rivet. The improved geometry can be manufactured by cold forming and fed by standard equipment. The special features of the improved rivet geometry are its large hole depth and bevelled rivet shank. The possibility of reliably joining both material combinations with the improved rivet geometry is verified in experimental tests. In the context of the project referred to under Acknowledgements below, rivets based on the improved geometry are being developed in austenitic stainless steel with high strain hardening. These rivets will be compared to the series rivets used for sampling and the improved rivets from the present investigation in future studies that are to be conducted of the deformation behaviour of the rivet, the material flow during the joining process and the quality and the strength of the resulting joint.

Acknowledgements Open Access funding provided by Projekt DEAL. The authors would like to thank the German Research Foundation (DFG) for their support of the research project "Forming and joining of semi-tubular self-piercing rivets made of high-strength steel with adapted mechanical properties and numerical analysis of the process chain" (ME 1840/8-1), on which this paper is based.

Open Access This article is licensed under a Creative Commons Attribution 4.0 International License, which permits use, sharing, adaptation, distribution and reproduction in any medium or format, as long as you give appropriate credit to the original author(s) and the source, provide a link to the Creative Commons licence, and indicate if changes were made. The images or other third party material in this article are included in the article's Creative Commons licence, unless indicated otherwise in a credit line to the material. If material is not included in the article's Creative Commons licence and your intended use is not permitted by statutory regulation or exceeds the permitted use, you will need to obtain permission directly from the copyright holder. To view a copy of this licence, visit http://creativecommons.org/licenses/by/4.0/.

\section{References}

1. Gude M, Lieberwirth H, Meschut G, Zäh M (2015) FORELStudie Chancen und Herausforderungen im ressourceneffizienten Leichtbau für die Elektromobilität

2. Michalos G, Makris S, Papakostas N, Mourtzis D, Chryssolouris G (2010) Automotive assembly technologies review: challenges and outlook for a flexible and adaptive approach. CIRP J Manuf Sci Technol 2(2):81-91

3. Barnes TA, Pashby IR (2000) Joining techniques for aluminium spaceframes used in automobiles: Part II - adhesive bonding and mechanical fasteners. J Mater Process Technol 99(1-3):72-79 
4. Mortimer J (2006) Jaguar uses castings, extrusions to reduce parts count in new sports car. Assembly Automat 26(2):115-120

5. Li D, Chrysanthou A, Patel I, Williams G (2017) Self-piercing riveting - a review. Int J Adv Manuf Technol 92:1777-1824

6. DVS/EFB 3410 (2019) Merkblatt Stanznieten - Überblick. DVS Media, Düsseldorf

7. Mori K, Abe Y (2018) A review on mechanical joining of aluminium and high strength steel sheets by plastic deformation. Int J Lightweight Mater Manuf 1(1):1-11

8. Mori K, Kato T, Abe Y, Ravshanbek Y (2006) Plastic joining of ultra high strength steel and aluminium alloy sheets by self piercing rivet. CIRP Ann Manuf Technol 55(1):283-286

9. Abe Y, Kato T, Mori K (2009) Self-piercing riveting of high tensile strength steel and aluminium alloy sheets using conventional rivet and die. J Mater Process Technol 209(8):3914-3922

10. Li D, Han L, Shergold M, Thornton M, Williams G (2013) Influence of rivet tip geometry on the joint quality and mechanical strengths of self-piercing riveted aluminium joints. Mater Sci Forum 765:746-750

11. Philipskötter A (2006) Entwicklung eines Halbhohlstanznietes für das Fügen von Mischbauweisen aus Aluminium und höherfesten Stählen. Dissertation, Paderborn University

12. Carandente M, Dashwood R, Masters I, Han L (2016) Improvements in numerical simulation of SPR process using a thermomechanical finite element analysis. J Mater Process Technol 236:148-161
13. Hockett JE, Sherby OE (1975) Large strain deformation of polycrystalline metals at low homologous temperatures. J Mech Phys Solid 23(2):87-98

14. Cockroft MG, Latham DJ (1968) Ductility and the workability of metals. J Inst Metals 96:33-39

15. Porcaro R, Hanssen AG, Langseth M, Aalberg A (2006) Selfpiercing riveting process: an experimental and numerical investigation. J Mater Process Technol 171:10-20

16. Falk T, Jäckel M (2019) Increasing flexibility of self-pierce riveting using numerical and statistical methods. Procedia Manuf 29:264-270

17. Drossel WG, Jäckel M (2014) New die concept for selfpiercing riveting materials with limited ductility. KEM 611-612:1452-1459

18. Eckstein J (2009) Numerische und experimentelle Erweiterung der Verfahrensgrenzen beim Halbhohlstanznieten hochfester Bleche. Dissertation, University of Stuttgart

19. Haque R (2014) Residual stress and deformation in SPR joints of high strength materials. Dissertation, Swinburne University

Publisher's Note Springer Nature remains neutral with regard to jurisdictional claims in published maps and institutional affiliations. 